SUPPORTING INFORMATION

\title{
LEWIS ACID-MEDIATED COPOLYMERIZATION OF METHYL ACRYLATE AND METHYL METHACRYLATE WITH 1-ALKENES
}

Megan Nagel, Dawn Poli, and Ayusman Sen*

Department of Chemistry

The Pennsylvania State University

University Park, Pennsylvania 16802

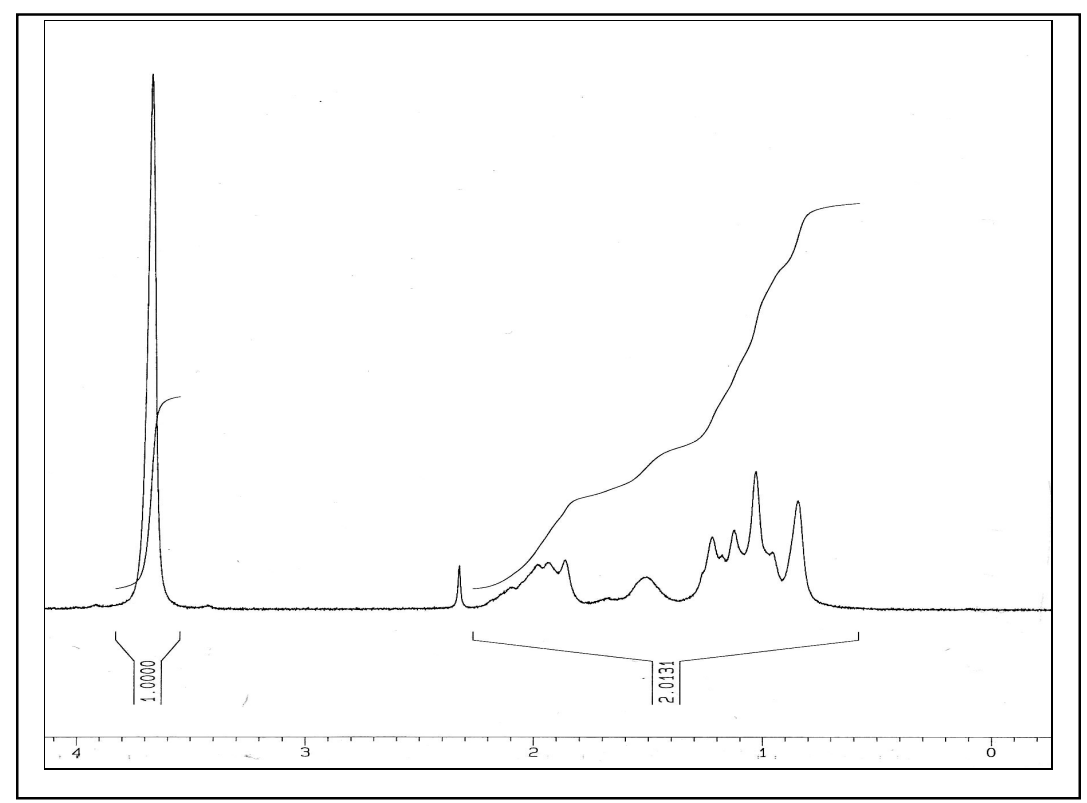

Figure S1. $300 \mathrm{MHz}{ }^{1} \mathrm{H} \mathrm{NMR}$ spectrum $\left(\mathrm{CDCl}_{3}\right)$ of methyl methacrylate (MMA)/ethene copolymer. 


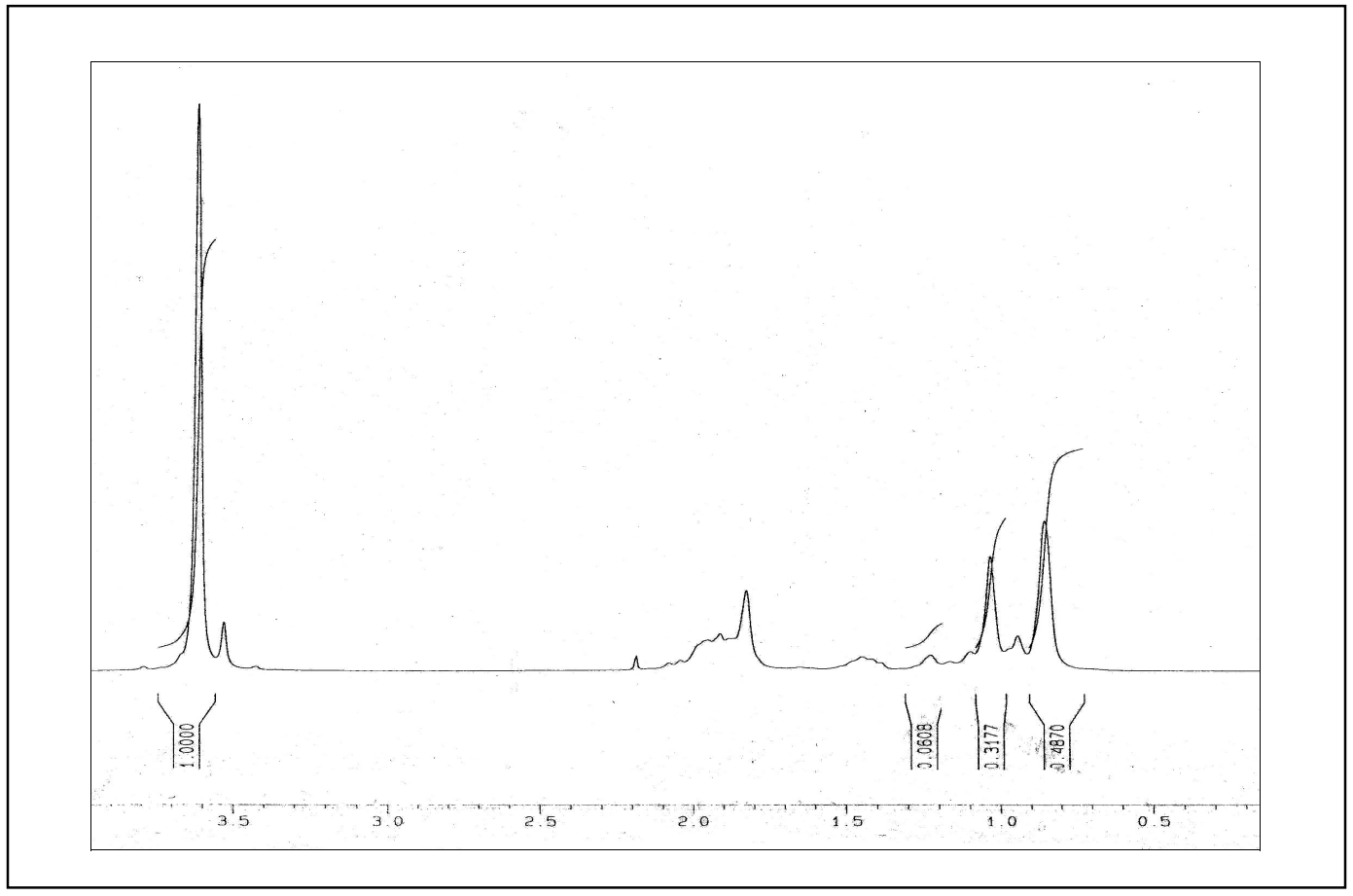

Figure S2. $300 \mathrm{MHz}{ }^{1} \mathrm{H} \mathrm{NMR}$ spectrum $\left(\mathrm{CDCl}_{3}\right)$ of methyl methacrylate $(\mathrm{MMA}) / \mathrm{C}_{2} \mathrm{D}_{4}$ copolymer. 


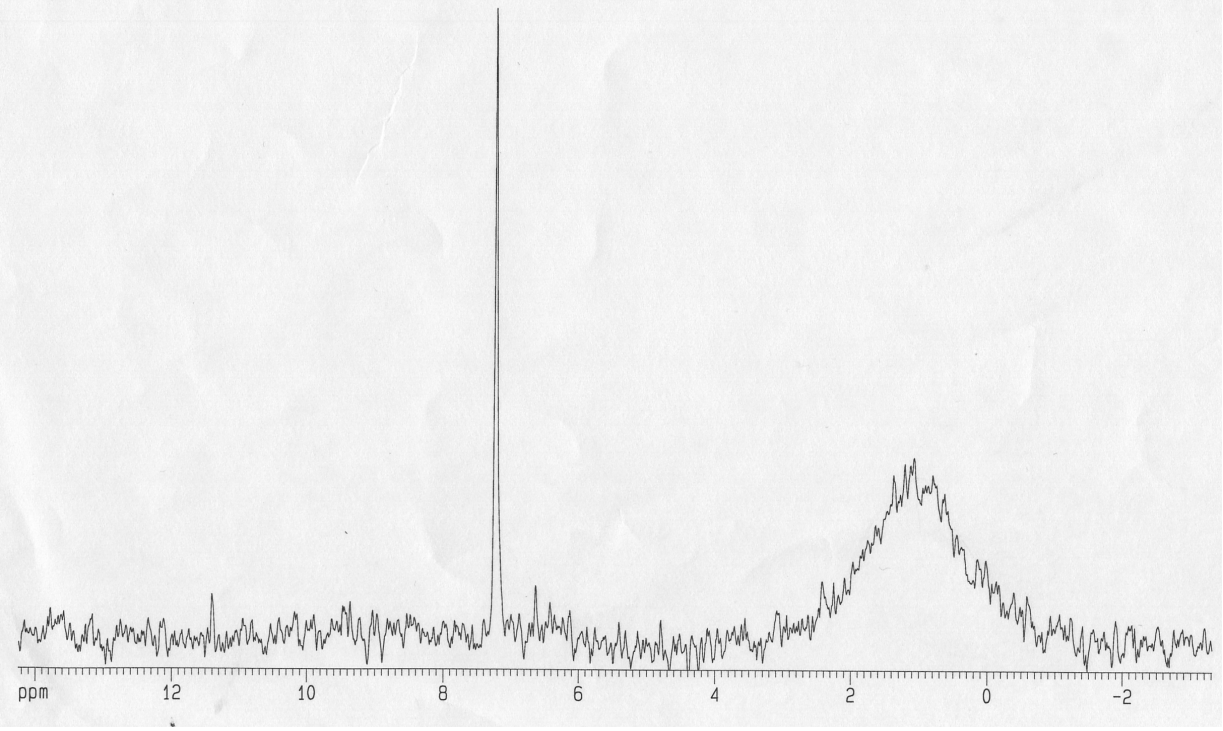

Figure S3. $46 \mathrm{MHz}{ }^{2} \mathrm{H}$ NMR spectrum $\left(\mathrm{CDCl}_{3}\right)$ of metheyl methacrylate $(\mathrm{MMA}) / \mathrm{C}_{2} \mathrm{D}_{4}$ copolymer. 


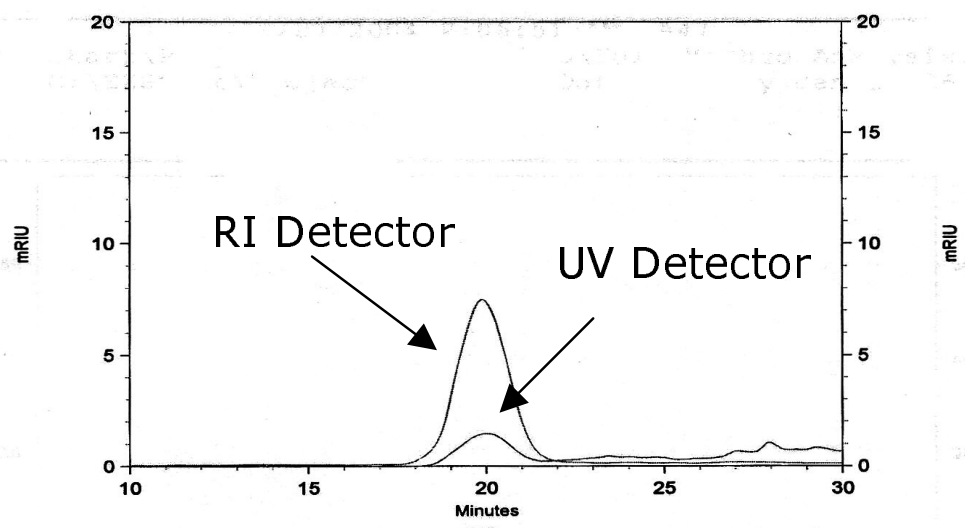

Figure S4. GPC traces of nearly alternating methyl acrylate (MA)/ethene copolymer using UV and refractive index (RI) detectors. 